\title{
Effectiveness of a universal parental support programme to promote health behaviours and prevent overweight and obesity in 6-year-old children in disadvantaged areas, the Healthy School Start Study II, a cluster-randomised controlled trial
}

Gisela Nyberg ${ }^{1,2^{*}}$, Åsa Norman ${ }^{1}$, Elinor Sundblom ${ }^{1,2}$, Zangin Zeebari ${ }^{1,2}$ and Liselotte Schäfer Elinder ${ }^{1,2}$

\begin{abstract}
Background: There is increasing evidence for the effectiveness of parental support programmes to promote healthy behaviours and prevent obesity in children, but only few studies have been conducted among groups with low socio-economic status. The aim of this study was to develop and evaluate the effectiveness of a parental support programme to promote healthy dietary and physical activity habits and to prevent overweight and obesity in six-year-old children in disadvantaged areas.

Methods: A cluster-randomised controlled trial was carried out in disadvantaged areas in Stockholm. Participants were six-year-old children $(n=378)$ and their parents. Thirty-one school classes from 13 schools were randomly assigned to intervention $(n=16)$ and control groups $(n=15)$. The intervention lasted for 6 months and included: 1) Health information for parents, 2) Motivational Interviewing with parents and 3) Teacher-led classroom activities with children. Physical activity was measured by accelerometry, dietary intake and screen time with a questionnaire, body weight and height were measured and BMI standard deviation score was calculated. Measurements were conducted at baseline, post-intervention and at 5 months follow-up. Group effects were examined using Mixed-effect Regression analyses adjusted for sex, parental education and baseline values.

Results: Fidelity to all three intervention components was satisfactory. Significant intervention effects were found regarding consumption of unhealthy foods $(p=0.01)$ and unhealthy drinks $(p=0.01)$. At follow-up, the effect on intake of unhealthy foods was sustained for boys $(p=0.03)$. There was no intervention effect on physical activity. Further, the intervention had no apparent effect on BMI sds for the whole sample, but a significant difference between groups was detected among children who were obese at baseline $(p=0.03)$ which was not sustained at follow-up.

(Continued on next page)
\end{abstract}

\footnotetext{
* Correspondence: gisela.nyberg@ki.se

${ }^{1}$ Department of Public Health Sciences, Karolinska Institutet,

Tomtebodavägen 18 A, 17177 Stockholm, Sweden

${ }^{2}$ Centre for Epidemiology and Community Medicine, Stockholm County

Council, Box 149717129 Solna, Sweden
} 
(Continued from previous page)

Conclusions: The Healthy School Start study shows that it is possible to influence intake of unhealthy foods and drinks and weight development in obese children by providing individual parental support in a school context. However, the effects were short-lived. Therefore, the programme needs to be prolonged and/or intensified in order to obtain stronger and sustainable effects. This study is an important contribution to the further development of evidence-based parental support programmes to prevent overweight and obesity in children in disadvantaged areas.

Keywords: Physical activity, Diet, Sedentary behaviour, Accelerometer, BMI, Intervention, Socio-economic status, Parental education, Motivational interviewing, Pre-school class

\section{Background}

Insufficient physical activity and poor dietary habits are important lifestyle factors causing chronic diseases worldwide, including obesity [1]. Studies show that health-related behaviours [2-4] and obesity [5] track from childhood to adolescence and adulthood. This might lead to serious health consequences later in life, such as metabolic disturbances, type-2 diabetes, cardiovascular diseases, certain cancers and impaired mobility [6]. Furthermore, children of obese parents often develop a similar weight pattern, and low socio-economic status (SES) is one of the strongest determinants [7].

In Sweden, as in many high income countries, there are large social inequalities in dietary habits, physical activity and prevalence of obesity to the disadvantage of children from families with low SES $[8,9]$. Children living in deprived areas have approximately three times greater risk of becoming obese than children living in affluent areas $[8,10]$, pointing to the importance of social factors. Therefore, interventions targeting health-related behaviours and obesity should focus on both social and environmental determinants and start from an early age. Parents and factors in the home environment are important for children's dietary habits [11-14] and physical activity [15-18]. Moreover, lower SES is associated with poorer eating habits [19]. A Swedish study shows that already from grade 2 (age 8), there are clear differences in eating habits depending on the parents' educational background [20]. In contrast, most studies done among young children, find no association between parental SES and physical activity $[16,21]$.

In order to reach all children, irrespective of family background, schools are the preferred setting for health promotion. The effectiveness of school-based programmes can be enhanced by including a parental component [22]. In recent years, evidence has been accumulating for parental support programmes to promote healthy dietary and physical activity habits in school children [23-25]. Furthermore, a number of successful parental support programmes with [26] or without a school component suggest greater effectiveness the lower the age of the participating child [27]. A review about parental involvement in efforts to improve children's diet concluded that most interventions used indirect methods such as sending home newsletters, but that direct approaches such as group education were more likely to be effective [24]. A review of parental support interventions targeting children's health behaviours showed that individual counselling with parents was effective in improving children's dietary habits but less effective in increasing physical activity [27]. The review also showed that in minority groups and groups with low SES, intensive parental support given in group educational settings is promising, but low participation and attrition remain a challenge. Moreover, few studies had used an individual counselling approach with parents in disadvantaged groups.

Young children have a limited cognitive capacity for decision making and therefore rely on care-givers. It has been suggested that parental self-efficacy (PSE) impacts child behaviour both directly and indirectly via parenting practices and behaviours, and that PSE may be an appropriate target for intervention [28]. One way to improve PSE could be through Motivational Interviewing (MI), a method used to support behaviour change [29]. There is evidence that MI may improve dietary and physical activity habits in adults and enhance weight loss in overweight and obese patients [30-32]. Little is yet known of the effectiveness of MI as a way of influencing parents to improve health related behaviours of their children, but studies suggest that MI may increase parents' understanding of their children's weight problems and their motivation to improve their children's health habits [33, 34]. MI has also been suggested as a strategy to support constructive parenting skills in general [35].

The aim of this study was to evaluate the effectiveness of the 6-month Healthy School Start parental support programme targeting dietary habits, physical activity and body weight of six-year-old children in families with low socio-economic status in the school context.

\section{Methods}

Study design, randomisation, setting and participants

The intervention A Healthy School Start has been evaluated previously in an area with low to medium socioeconomic status [36, 37]. Based on experiences from the first study, we designed this second study as a cluster- 
randomised controlled trial with waiting-list control group. The unit of randomisation was pre-school class. Schools were chosen from low income areas in a municipality in Stockholm County, Sweden, with the highest prevalence of overweight and obesity among children in the county [38]. These areas are characterised by a high proportion of foreign-born citizens. This study involved 378 six-year-old children in pre-school class.

Figure 1 shows participant recruitment and retention. Of the 15 eligible schools ( $n=801$ children) in three lowincome areas, 13 schools and 31 pre-school classes participated. All families who had children in these classes were invited to participate in the study. The classes were randomly assigned to intervention $(n=16)$ or waiting-list control group $(n=15)$ after baseline measurement. Each class was assigned a number which was drawn randomly from a basket by an independent person in the presence of the research team. Every other school class was assigned to the intervention group. The children were recruited in August to September 2012, the intervention started in October and lasted for six months (2012-2013). Pre-school class is not compulsory in Sweden but 90-95 \% of all six-year-old children attend.

Written consent was collected from all parents of participating children. The study was approved by the
Regional Ethical Review Board in Stockholm, Sweden $(2012 / 877-31 / 5)$ on the $14^{\text {th }}$ of June, 2012. The trial has been registered: ISRCTN39690370.

\section{Theory}

It is widely recommended that programme design should be based on theory [39] where a theoretical framework supports the identification of the causal chain and possible mediators. Social cognitive theory (SCT) explains behaviour as a reciprocal interaction between person, behaviour, and environmental factors [40, 41]. A central construct in SCT is self-efficacy, a person's belief in his or her ability to successfully perform a certain action. In this programme we targeted parental self-efficacy (PSE), which refers to a parents' belief in his or her own ability to perform specific action for example serving vegetables to each meal eaten at home. Other important constructs in the SCT, relevant for our intervention, are observational learning, behavioural capability, outcome expectations and selfregulation. In this programme PSE, parental knowledge, attitude, preference, care and control, role modelling and willingness to change were identified as potential mediators of change regarding children's dietary and physical activity habits and weight development. Based on this analysis, three intervention components were defined and

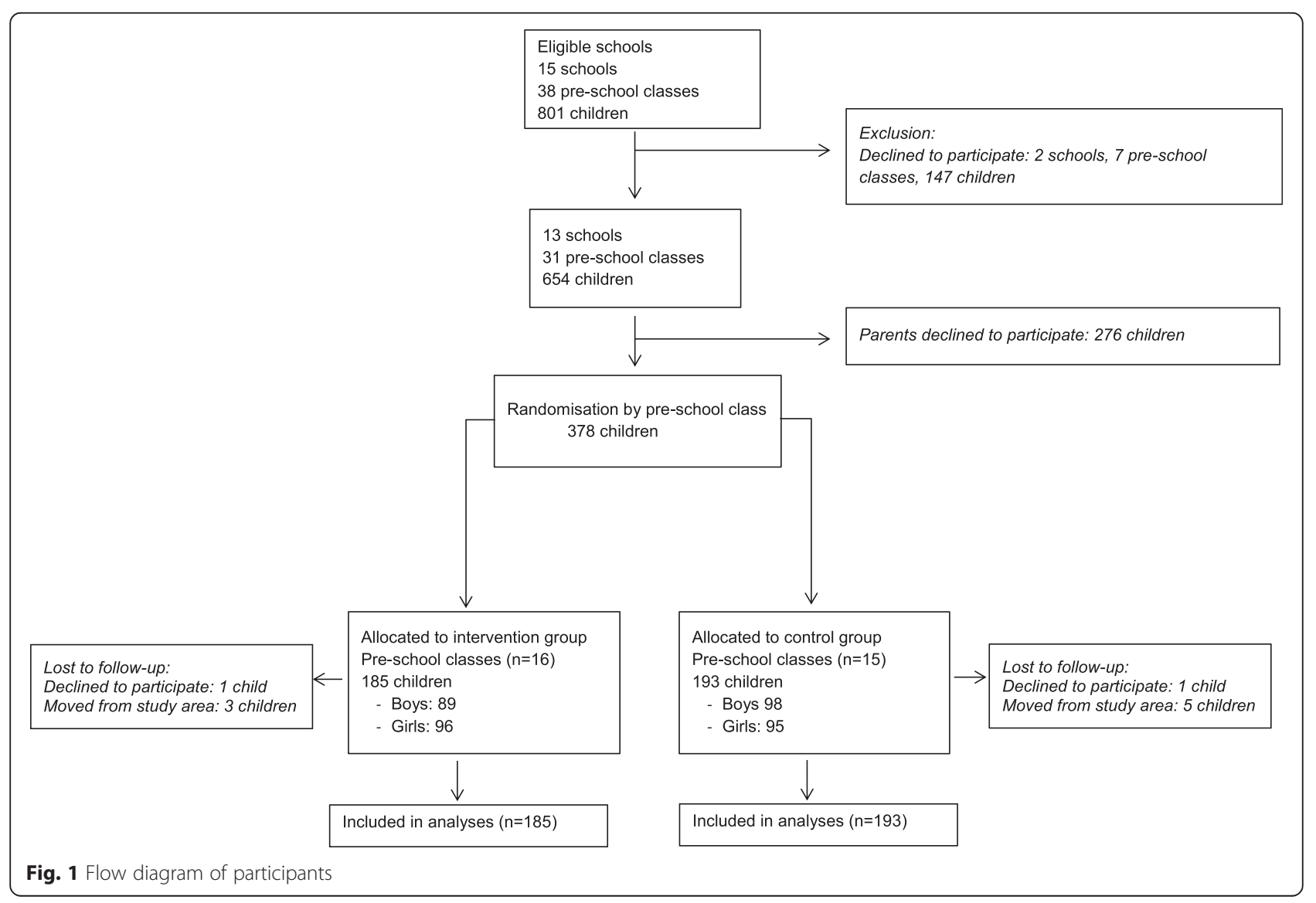


materials developed according to the steps of intervention research relevant to this study [42]. The intervention components were: 1) A brochure with health information targeting parental knowledge; 2) Motivational interviewing targeting parental self-efficacy, willingness to change and care and control; and 3) classroom activities targeting children's knowledge, attitudes and preferences and indirectly parental role modelling. A study protocol has been published describing this in more detail [37].

\section{Intervention components Health information}

A brochure was developed based on a literature review [43] with the aim of increasing parental knowledge regarding how to promote children's healthy dietary and physical activity habits. The brochure contains facts and advice for parents within seven areas: 1) parental feeding practices; 2) healthy food and family meal times; 3 ) physical activity; 4) sweets, snacks, ice-cream and soft drinks; 5) fruit and vegetables; 6) physical inactivity, screen time, and commercials; 7) sleep. The brochure is written in basic, easy-to-read Swedish with many illustrations. The brochure was translated into Arabic and Somali, the two most common languages in the intervention area and checked by two Arabic and Somali speaking persons and thereafter revised. The brochure was sent home to parents. Group meetings were offered once at each school, giving parents an opportunity to discuss the content of the brochure with two research assistants.

\section{Motivational interviewing}

MI was used to target PSE to support healthy eating and physical activity for the child, parental care and control, and stimulate parental willingness to change. MI is a client-centred, goal-oriented communication style designed to strengthen personal motivation for a specific behaviour change [29]. In MI, self-efficacy is a central part of motivation and is therefore focusing on ensuring that a person has high self-efficacy for changing a specific behaviour.

Parents in the intervention group were offered two individual sessions of MI without the presence of the child. Two MI counsellors performed the sessions, which lasted for approximately $45 \mathrm{~min}$. The parents met the same MI counsellor both times. During the first MI session, the parents used an agenda-setting tool to choose a target behaviour involving their child's diet or physical activity that they wanted to change. This behaviour was subsequently explored together with the MI counsellor and the parent set a goal related to the target behaviour to work on at home until the second MI session, which served as a follow-up. The second session was offered either face-to-face or over the telephone at the parent's choice. The MI sessions provide the most intense parental support and are therefore hypothesised to be the component of the Healthy School Start intervention with greatest impact on outcome.

\section{Classroom activities}

The aim of the classroom component was to increase children's knowledge, influence their attitudes and preferences, and indirectly support parental role modelling. A teacher's manual and a workbook for children were developed to facilitate the classroom activities, which were related to the different areas in the brochure sent home to parents. The materials were developed together with teachers and inspired by earlier school interventions $[44,45]$. Before the start of the intervention, the workbooks were read and commented on by eleven parents of grade 1 children in two of the participating schools. The manuals were tested by four teachers in the participating schools.

The children were exposed to ten 30-min teacher-led sessions. The teachers were provided with a tool-box containing culturally appropriate images of common food products such as baklava, olives and bulgur wheat, and used the teaching manual for each session. After most sessions, the children were given homework to discuss and complete together with their parents. Back in the classroom, the teachers and children summarised the homework, so that each theme was repeated.

Control classes were offered the entire programme after the follow-up measurements were completed.

\section{Implementation strategies}

The following implementation strategies were used:

Schools: The principals in each school signed a contract with the research group specifying the obligations and commitments of the schools and the research team.

MI counsellors: The two MI counsellors had training and professional experience of $\mathrm{MI}$ and met a satisfactory level of MI competence according to the Motivational Interviewing Treatment Integrity (MITI 3.0) Code [46] at the time of recruitment. The counsellors received additional training and were supervised nine times during the intervention by a member of the Motivational Interviewing Network of Trainers and part of the research team (ÅN). Supervision focused on the counsellors' experiences and difficulties when performing MI with the parents and also included systematic feedback and MITI-coding on audiotaped MI sessions.

Teachers: The research team trained the teachers for the classroom activities for two hours before the start of the intervention. In addition, teachers were given continuous support by the research team through face-to face contact, telephone and e-mail throughout the intervention. 
Parents: Parents were informed about the project at the first regular information meeting in school. When the intervention had started, an additional meeting was offered at each school for parents in the intervention group, where they could discuss issues related to diet and physical activity.

\section{Outcome evaluation}

Data were collected at baseline between August and September 2012 (T1), directly after the intervention between April and May 2013 (T2) and at follow-up five months after the intervention, between September and October 2013 (T3).

\section{Physical activity by accelerometry}

Physical activity was objectively assessed using accelerometry (GT3X+, Actigraph, LCC, Pensacola, USA). This method has been used in many studies to measure physical activity in children and is considered valid and reliable $[47,48]$. The accelerometers were worn on a belt at the right hip for seven consecutive days. The children were instructed to wear the monitors during waking hours and to remove them for activities involving water.

The software ActiLife Data Analysis, version 6.5.2., was used to analyse the accelerometer data. Physical activity was assessed between 7 am and 9 pm and was calculated for the whole week and during weekends. Children who provided at least 500 min of activity registration per day for a minimum of two days, including at least one weekend day, were included in the analyses. Data were defined as non-wear time and excluded if sequences showed 10 or more consecutive minutes of zero counts. The epoch length was set to $15 \mathrm{~s}$. The threshold for sedentary intensity was defined as all activity below $100 \mathrm{cpm}[49,50]$, moderate to vigorous intensity was defined as all activity above $2000 \mathrm{cpm}$. The threshold for moderate intensity corresponds to a walking pace of about $4 \mathrm{~km} / \mathrm{h}$ (3 METS) in children [51].

\section{Health behaviours by parent report}

Dietary indicators (fruit, vegetables and energy-dense products), physical activity habits, sedentary behaviour and sleep were measured through a validated parentproxy questionnaire, the Eating and Physical Activity Questionnaire (EPAQ) [52], which was translated into Swedish and to some extent adapted to a Swedish context. Parents were asked to recall the child's intake of selected indicator foods (snacks, sweets/chocolate, icecream, cakes/buns/cookies, fruits, vegetables, soft drink, flavoured milk and fruit juice) the previous weekday. For each food item the parent marked the number of servings on a scale with 7 categories: $0,0.5,1,2,3,4,5$. For drink items the categories were: $0,1,2,3,4,5,6$ or more servings. Servings were defined as: drinks $=1.5 \mathrm{dl}$, vegetables = e.g. $2 \mathrm{dl}$ grated carrots/cabbage or a big tomato or 2-3 broccoli stalks, fruit =e.g. a small apple or about 10 grapes, snacks $=1.5 \mathrm{dl}$ crisps or cheese doodles, sweets = about $1.5 \mathrm{dl}$ of sweets or 4 pieces from a chocolate bar, cakes $=\mathrm{a}$ small bun or 5 small biscuits, ice-cream $=$ a small popsicle stick or $1 \mathrm{dl}$ ice-cream. The questionnaire has previously been validated against 24-h dietary recall in two to fiveyear-old children and showed significant Spearman rank correlations for different items ranging from 0.57 to 0.88 [52]. The Swedish language in the questionnaire was pre-tested by eleven parents of grade 1 children in two of the participating schools and the language was simplified where necessary. The EPAQ was distributed by mail to the parents and only available in Swedish. Parents were offered help to fill in the questionnaires on one occasion at each school.

\section{Anthropometry}

Height, weight and waist circumference measurements were performed in schools by two trained research assistants according to standardised procedures [37]. BMI was calculated as weight $(\mathrm{kg})$ divided by height (m) squared. Overweight and obesity were defined according to the International Obesity Task Force recommendations [53]. BMI standard deviation score (BMI sds) was calculated according to a Swedish reference standard [54].

\section{Socio-economic status}

Area of residence and parental educational level were used as indicators of SES $[55,56]$. The study was conducted in three areas in Stockholm County with low employment and low educational level. These areas are also targeted specifically by the government to support socioeconomic development [57]. Parental educational level was self-reported and the highest level of education attained by either of the parents was used as an indicator of SES. The variable was dichotomised with low education corresponding to primary and secondary school ( $\leq 12$ years of schooling) and high ( $>12$ years of schooling) corresponding to third level education.

\section{Region of birth}

Parents were also asked to indicate their region of birth as "Sweden/the Nordic region", "Europe" or "Outside Europe". It was also possible to specify the country.

\section{Process evaluation}

The process of the intervention was assessed as the dose the parents had received and the dose the teachers had delivered. Parents were asked at the first MI session if they had read the brochure. Teachers were asked whether they had completed the teaching sessions and 
workbooks and also documented how much time they had spent on each session. Fidelity to MI was measured through coding of sessions. All MI sessions were audiorecorded and each counsellor had eight sessions coded according to MITI 3.0 [46] by reliable coders at a university coding lab (MIC-Lab, Stockholm). Mean values on the MI behaviours measured by the MITI were calculated for each MI counsellor and compared to threshold values for acceptable delivery of MI.

The teachers in the control classes were continuously asked to document if they had engaged in any organised healthy lifestyle activities during the intervention, in order to monitor possible contamination.

\section{Statistical analyses}

Descriptive data at baseline were analysed using the SPSS 22.0 software package (Chicago, Illinois, USA). Significance-testing for differences between intervention and control group at baseline was performed through independent sample $t$-test or Chi-square/Mann-Whitney $U$-Test. All children who had agreed to participate in the intervention were included in the analysis on an intention to treat basis. Analyses were also performed per protocol where families participating in one or two MI session were compared to the control group.

Prior to analyses, half-servings of the dietary indicators were slightly modified to fit a Poisson distribution by merging half-servings with single-servings. A sensitivity analysis was performed where half-servings were merged with zero-servings, with no differences in results. We also created aggregated variables indicating unhealthy foods (snacks, sweets/chocolate, ice-cream, cakes/buns/ cookies), healthy foods (fruit and vegetables) and unhealthy drinks (soft drink, flavoured milk and fruit juice above one serving) to analyse food patterns. When aggregating the separate variables we used the original values, containing half-servings, in order to retain as much information as possible. After aggregation, an adjustment of the half-servings was made by merging them with the closest upper discrete value. Sensitivity assessment was performed by merging half-servings with the closest lower discrete value, which gave similar results.

School class was used as unit of randomisation and therefore Mixed-effect Regression analyses [58] with two levels (individual and school class) were undertaken to estimate the intervention effects. For continuous outcomes (total physical activity during the week and weekend (TPA), time spent in moderate to vigorous physical activity during the week and weekend (MVPA), time spent sedentary during the week and weekend, screen time, BMI sds) Mixed Linear Regression was performed. For count outcomes (servings of juice, soft drink, flavoured milk, vegetables, snacks, fruits, sweets, cakes and ice-cream consumed on the previous day) Mixed
Poisson Regression was performed. The statistical software MLwiN (version 2.31, 2014, Bristol University) was used. Level of significance was set to $\mathrm{p}<0.05$.

In order to detect significant changes between the groups after the intervention and to see if the changes were maintained at follow-up we compared the measurement at baseline (T1) to the measurement after the intervention (T2) and then compared T1 with the follow up measurement (T3). At the latter analysis, we excluded those individuals who did not have values at $\mathrm{T} 2$ in order to perform both comparisons (T1-T2 and T1-T3) on the same individuals.

We first tested a crude model for all outcomes at T2 or T3 with group as the predictor and adjusted for baseline values of the relevant outcome. In a second step, sex and parental education were added to the model. Interaction between group and sex or group and parental education were tested and analyses were stratified if significant interaction terms were found. Regarding physical activity (TPA, MVPA and time spent sedentary) outcomes were also adjusted for accelerometer monitor wear time. In the case of sedentary outcomes (week and weekend) the outcomes were adjusted for MVPA during the same period [59]. Since $80.4 \%$ of the parents were born outside the Nordic region, we also tested the models by adjusting for region of birth (a dichotomous variable: Nordic/outside Nordic). Region of birth was not significant in any of the analyses and was therefore not used in the final models. Lastly, a random intercept for school class clustering was tested to detect differences between the clusters. To assess the fit of the model, we compared -2 Log Likelihood values between the model with fixed main effects and the model where the random intercept was included. A sensitivity analysis was undertaken for significant outcomes (unhealthy foods and unhealthy drinks, cakes/buns/cookies, and BMI sds) where baseline values were imputed for missing data at $\mathrm{T} 2$ or $\mathrm{T} 3$.

The power calculation for this study was based on the assumption of an average $20 \%$ increase of physical activity assessed by accelerometry in the intervention group. The estimated sample size was calculated for a twosided test with the significance level of 0.05 and power was set to $90 \%$ using a sample size calculator for cluster randomised trials [60]. The calculation showed that 12 school classes with a participation rate of $60 \%$ in each class, approximately 144 children in total, were needed to detect a $20 \%$ increase in physical activity between the intervention and control groups.

\section{Results}

Ten children dropped out of the study (intervention: 4, control: 6). These children had weight status and parental education levels similar to the remaining sample. 
Families classified as having low parental education comprised $47.1 \%$ of the total sample. Of all the parents, $80.4 \%$ were born outside of the Nordic region with Iraq, Eritrea, Somalia, Iran and Turkey as the most common countries of birth.

Table 1 shows descriptive data and results of independent sample $t$-test and Chi-square-test at baseline.
There were no significant baseline differences between the groups, except for intake of ice-cream, chocolate and sweets; with children in the control group consuming significantly more than those in the intervention group. Also, the proportion of parents born outside of the Nordic region was higher in the control group.

Table 1 Descriptive characteristics of children at baseline categorised by intervention and control group

\begin{tabular}{|c|c|c|c|c|c|}
\hline & Total & Intervention & Control & $p$ & $n$ \\
\hline & $n=378$ & $n=185$ (89 boys $/ 96$ girls) & $n=193$ (98 boys $/ 95$ girls) & & \\
\hline & Mean (SD) & Mean (SD) & Mean (SD) & & \\
\hline Age (years) & $6.3(0.3)$ & $6.3(0.3)$ & $6.3(0.3)$ & 0.84 & 378 \\
\hline Parental low education per family (\%) & 47.1 & 43.8 & 50.3 & 0.18 & 345 \\
\hline Parents born outside the Nordic region (\%) & 80.4 & 76.5 & 84.2 & 0.01 & 699 \\
\hline \multicolumn{6}{|l|}{ Anthropometry } \\
\hline Weight (kg) & $24.5(5.0)$ & $24.2(5.0)$ & $24.7(5.0)$ & 0.33 & 378 \\
\hline Height (cm) & $120.3(5.4)$ & $119.9(5.1)$ & $120.6(5.7)$ & 0.23 & 378 \\
\hline Waist circumference $(\mathrm{cm})$ & $56.2(5.7)$ & $56.1(5.7)$ & $56.6(5.7)$ & 0.44 & 378 \\
\hline Body mass index (kg/m2) & $16.8(2.5)$ & $16.7(2.4)$ & $16.9(2.5)$ & 0.51 & 378 \\
\hline BMI sds ${ }^{\mathrm{a}}$ & $0.66(1.37)$ & $0.62(1.33)$ & $0.69(1.42)$ & 0.60 & 378 \\
\hline Normal weight ${ }^{\mathrm{b}}(\%)$ & 67.5 & 68.6 & 66.3 & 0.63 & 378 \\
\hline Overweight and obese ${ }^{\mathrm{b}}(\%)$ & 26.5 & 25.4 & 27.5 & 0.65 & 378 \\
\hline Underweight ${ }^{\mathrm{b}}(\%)$ & 6.1 & 5.9 & 6.2 & 0.91 & 378 \\
\hline \multicolumn{6}{|l|}{ Physical activity } \\
\hline TPA, all week (cpm) & 775 (192) & $792(218)$ & $758(160)$ & 0.11 & 327 \\
\hline TPA, weekend (cpm) & $639(207)$ & $627(211)$ & $651(204)$ & 0.34 & 268 \\
\hline MVPA, all week (minutes) & $89(24)$ & $89(25)$ & $88(23)$ & 0.82 & 327 \\
\hline MVPA, weekend (minutes) & $66(27)$ & $64(27)$ & $69(26)$ & 0.15 & 268 \\
\hline Sedentary, all week (minutes) & $322(45)$ & $318(48)$ & $326(42)$ & 0.08 & 327 \\
\hline Sedentary, weekends (minutes) & $326(64)$ & $327(65)$ & $325(64)$ & 0.71 & 268 \\
\hline $\begin{array}{l}\text { Child taken to playground etc in the } \\
\text { past week (times/week) }\end{array}$ & $2.04(1.27)$ & $2.00(1.27)$ & $2.09(1.29)$ & 0.57 & 291 \\
\hline Television/computer time (minutes/day) & $128(75)$ & $124(77)$ & $133(72)$ & 0.34 & 301 \\
\hline \multicolumn{6}{|l|}{ Diet (servings the previous day) } \\
\hline Fruit juice & $0.57(0.66)$ & $0.56(0.69)$ & $0.57(0.62)$ & 0.72 & 253 \\
\hline Soft drink & $0.29(0.52)$ & $0.26(0.49)$ & $0.32(0.54)$ & 0.32 & 232 \\
\hline Milk & $1.21(0.78)$ & $1.16(0.76)$ & $1.26(0.80)$ & 0.18 & 280 \\
\hline Flavoured milk & $0.33(0.56)$ & $0.28(0.45)$ & $0.38(0.65)$ & 0.36 & 227 \\
\hline Vegetables & $1.03(0.77)$ & $0.95(0.76)$ & $1.11(0.79)$ & 0.28 & 277 \\
\hline Fruits & $1.62(0.96)$ & $1.48(0.85)$ & $1.76(1.05)$ & 0.14 & 294 \\
\hline Snacks (crisps and cheese doodles) & $0.31(0.61)$ & $0.27(0.52)$ & $0.36(0.68)$ & 0.26 & 263 \\
\hline Chocolate/sweets & $0.47(0.68)$ & $0.36(0.62)$ & $0.57(0.72)$ & 0.05 & 276 \\
\hline Ice-cream & $0.49(0.76)$ & $0.35(0.61)$ & $0.64(0.87)$ & 0.03 & 281 \\
\hline Cake/buns/cookies & $0.57(0.79)$ & $0.51(0.61)$ & $0.64(0.80)$ & 0.43 & 274 \\
\hline
\end{tabular}

$p=$ between intervention and control groups

$B M I$ sds body mass index standard deviation score, TPA total physical activity, cpm counts per minute, MVPA moderate to vigorous physical activity

${ }^{a}$ Defined according to Karlberg et al. 2001

befined according to Cole et al. 2012 
Diet

The parental response rate to the questionnaire measuring dietary intake ranged from 78 to $60 \%$ for the different items at baseline, between 75 and $59 \%$ at T2 and between 72 and $59 \%$ at T3. At baseline $70 \%$ of the participating children consumed at least 2 servings of fruit and vegetables daily at home. Forty percent of the children consumed at least one serving of unhealthy foods daily, at baseline.

Regarding intake of indicator foods, we found significant intervention effects on outcomes related to intake of unhealthy foods and drinks (Table 2). At T2 the intervention group had a significantly lower intake of unhealthy foods (aggregated variable: snacks, ice-cream, cookies and sweets) $(p=0.01)$. This effect was sustained in boys at T3 $(p=0.03)$. Intake of unhealthy drinks (aggregated variable: soft drink, flavoured milk and fruit juice above 1 serving) at T2 was significantly lower in the intervention group ( $p=0.01)$ compared to the control group. This effect was not sustained at T3.

When each indicator food was assessed separately, an interaction effect with group and sex was found regarding intake of cakes/buns/cookies: boys in the intervention group had significantly lower intake at T2 compared to boys in the control group $(p=0.003)$. The differences were no longer significant at T3.

We noted a trend towards lower intake of all separate unhealthy food and drink outcomes in the intervention at T2, although none of them were significant. This trend was still visible at T3 for unhealthy foods but not for unhealthy drinks.

Regarding intake of healthy foods (aggregated variable: fruit and vegetables) we saw no significant differences between intervention and control groups either on the aggregated variable or the separate outcomes for fruit and vegetables.

Table 2 Effects of intervention on dietary intake of indicator foods at T2 and T3

\begin{tabular}{|c|c|c|c|c|c|c|c|c|c|c|}
\hline \multirow[b]{2}{*}{$\begin{array}{l}\text { Servings }{ }^{a} \text { the previous } \\
\text { weekday }\end{array}$} & \multirow[b]{2}{*}{$n$} & \multirow[b]{2}{*}{$b$} & \multicolumn{2}{|l|}{$\mathrm{T} 2$} & \multirow[b]{2}{*}{$\begin{array}{l}\text { Between school class } \\
\text { variance } \sigma_{u}^{2} \text { (s.e.) }\end{array}$} & \multirow[b]{2}{*}{$n$} & \multirow[b]{2}{*}{$b$} & \multicolumn{2}{|l|}{ T3 } & \multirow[b]{2}{*}{$\begin{array}{l}\text { Between school class } \\
\text { variance } \sigma_{u}^{2} \text { (s.e.) }\end{array}$} \\
\hline & & & $p$ & $95 \% \mathrm{Cl}$ & & & & $p$ & $95 \% \mathrm{Cl}$ & \\
\hline \multicolumn{11}{|l|}{ Separate variables } \\
\hline Fruit juice & 190 & -0.24 & 0.16 & -0.09 to 0.56 & $0.19(0.23)$ & 154 & -0.09 & 0.70 & -0.53 to 0.36 & $0.00(0.00)$ \\
\hline Soft drink/sugar syrup & 162 & -0.28 & 0.25 & -0.76 to 0.19 & $0.00(0.00)$ & 126 & 0.02 & 0.95 & -0.64 to 0.68 & $0.00(0.00)$ \\
\hline Flavoured milk & 161 & -0.47 & 0.15 & -1.11 to 0.16 & $0.00(0.00)$ & 131 & -0.04 & 0.92 & -0.76 to 0.68 & $0.00(0.00)$ \\
\hline Vegetables & 226 & 0.15 & 0.22 & -0.09 to 0.38 & $0.00(0.00)$ & 196 & 0.02 & 0.85 & -0.22 to 0.27 & $0.00(0.00)$ \\
\hline Snacks & 195 & -0.57 & 0.08 & -1.19 to 0.06 & $0.00(0.00)$ & 162 & -0.46 & 0.19 & -1.16 to 0.24 & $1.35(0.49)$ \\
\hline Fruits & 241 & -0.15 & 0.13 & -0.35 to 0.04 & $0.00(0.00)$ & 206 & 0.03 & 0.76 & -0.18 to 0.25 & $0.00(0.00)$ \\
\hline Sweets/chocolate & 210 & -0.38 & 0.10 & -0.82 to 0.07 & $0.00(0.00)$ & 173 & -0.26 & 0.29 & -0.73 to 0.21 & $0.00(0.00)$ \\
\hline Cakes/buns/cookies & 212 & 0.00 & 1.00 & -0.51 to 0.51 & $0.00(0.00)$ & 179 & -0.33 & 0.12 & -0.74 to 0.89 & $0.00(0.00)$ \\
\hline Girls $^{b}$ & 104 & -0.04 & 0.88 & -0.55 to 0.47 & $0.00(0.00)$ & & & & & \\
\hline Boys $^{b}$ & 108 & -0.95 & 0.003 & -1.58 to -0.32 & $0.00(0.00)$ & & & & & \\
\hline Ice-cream & 222 & -0.22 & 0.22 & -0.57 to 0.13 & $0.00(0.00)$ & 186 & -0.22 & 0.30 & -0.65 to 0.20 & $0.00(0.00)$ \\
\hline \multicolumn{11}{|l|}{ Aggregated variables ${ }^{c}$} \\
\hline Unhealthy food & 230 & -0.32 & 0.01 & -0.56 to -0.07 & $0.19(0.07)$ & 198 & -0.15 & 0.42 & -0.51 to 0.22 & $0.95(0.16)$ \\
\hline Girls $^{b}$ & & & & & & 101 & 0.19 & 0.43 & -0.28 to 0.67 & $0.79(0.19)$ \\
\hline Boys $^{b}$ & & & & & & 97 & -0.50 & 0.03 & -0.94 to -0.06 & $0.37(0.14)$ \\
\hline Unhealthy drink & 214 & -0.51 & 0.01 & -0.90 to -0.11 & $0.26(0.16)$ & 182 & 0.05 & 0.83 & -0.39 to 0.49 & $0.19(0.20)$ \\
\hline Healthy food & 248 & -0.02 & 0.79 & -0.16 to 0.12 & $0.00(0.00)$ & 217 & -0.03 & 0.68 & -0.18 to 0.12 & $0.00(0.00)$ \\
\hline
\end{tabular}

Results of Mixed Poisson Regression adjusted for sex, parental education and baseline value

$b=$ Regression coefficient (beta), $p=$ between intervention and control groups, $\mathrm{Cl}=95 \%$ confidence interval

a Serving sizes (examples below)

Drinks $=1.5 \mathrm{dl}$

Vegetables $=2 \mathrm{dl}$ grated carrots/cabbage or a big tomato or 2-3 broccoli stalks

Fruits $=$ a small apple or a bunch of grapes (about 10)

Snacks $=1.5 \mathrm{dl}$ of crisps or cheese doodles

Sweets = about $1.5 \mathrm{dl}$ of sweets or 4 pieces from a chocolate bar

Cakes = a small bun or 5 small biscuits

Ice-cream $=$ a small popsicle stick or $1 \mathrm{dl}$ ice-cream

${ }^{b}$ Stratified analysis due to interaction effect (group $\times$ sex)

'Aggregated variables: unhealthy foods (snacks, sweets/chocolate, ice-cream, cakes/buns/cookies), healthy foods (fruit and vegetables) and unhealthy drinks (soft drink, flavoured milk and fruit juice above one serving)

Subjects are dependent observations between $\mathrm{T} 1$ and $\mathrm{T} 2$ and between $\mathrm{T} 1$ and $\mathrm{T} 3$ 
All effects regarding intake of indicator foods at T2, unhealthy foods (aggregated variable), unhealthy drinks (aggregated variable), as well as the interaction effect on boys regarding cakes/buns/cookies (separate variable), were sustained in the sensitivity analyses after imputation of missing values. The same was true for the interaction effect on boys' intake of unhealthy foods (aggregated variable) at T3.

No interaction effects between group and parental education were found for any of the dietary outcomes.

\section{Physical activity}

The number of children who fulfilled the required level of at least 2 days (including one weekend day) of valid accelerometer data was 327 at baseline, 294 at T2 and 290 at T3. At baseline $290(89 \%)$ children reached $60 \mathrm{~min}$ of MVPA.

As shown in Table 3, no significant intervention effect was detected on any of the measurements of physical activity (TPA, MVPA, time spent sedentary and screen time) at $\mathrm{T} 2$.

At T3, significant intervention effects were detected in terms of time spent sedentary: the intervention group was sedentary $9.2 \mathrm{~min}$ less during the entire week $(p=0.03)$ and 11.3 min less during the weekend $(p=0.04)$. However, these effects were not sustained in the sensitivity analysis.

No interaction effects between group and parental education or group and sex were found for any of the physical activity outcomes.

\section{BMI}

Measurements on height, weight and waist circumference were performed on all (378) children at baseline, 359 at T2 and 345 at T3. There were no significant differences in BMI status in drop-outs between intervention and control group.

No significant intervention effect was detected for BMI sds at T2 or T3 (Table 4). However, a stratified analysis on weight status showed a significant intervention effect on children categorised as obese at baseline $(n=41)$. Children in the intervention group had significantly lower BMI sds $(-0.21 \mathrm{BMI}$ sds $)$ at T2 $(p=0.03)$ compared to obese children in the control group. This effect was stable in the sensitivity analysis but not sustained at T3 although the direction was still negative.

No interaction effects between group and parental education or group and sex were found regarding BMI.

\section{Per protocol analyses}

Analyses including only families participating in $1(n=147)$ or both MI sessions $(n=86)$ compared to the control group gave essentially the same results as presented above.

\section{Process evaluation}

All parents who attended the first MI session said they had read the brochure. Eleven group meetings with parents were undertaken where 45 parents participated.

The first MI session was performed with 146 parents (79 \%) of whom $65 \%$ were mothers, $31 \%$ were fathers and $4 \%$ participated as a couple. In the second session, 86 of the initial 146 parents participated. The level of MI delivered by the MI counsellors was satisfactory and is presented in Table 5.

In the 13 classes which reported their work with the classroom component, teachers spent on average $33 \mathrm{~min}$ on each lesson, ranging from 20 to $150 \mathrm{~min}$. Eleven classes performed all 10 lessons, 4 classes performed 9 lessons, and 1 class performed 8 lessons. Regarding the home assignments in the work book, 12 of the 16 intervention classes completed all 9 of the assignments, 1 class completed 8 assignments and 3 classes completed 1 to "a few" of the home assignments. However, the data do not show whether the assignments were completed at home, as intended, or at school.

As documented by teachers, control classes did not conduct any other organised healthy lifestyle activities in the control classes.

Table 3 Effects of the intervention on physical activity levels at T2 and T3

\begin{tabular}{|c|c|c|c|c|c|c|c|c|c|c|}
\hline & \multirow[b]{2}{*}{$n$} & \multicolumn{2}{|l|}{$\mathrm{T} 2$} & \multirow[b]{2}{*}{$95 \% \mathrm{Cl}$} & \multirow[b]{2}{*}{$\begin{array}{l}\text { Between school class } \\
\text { variance } \sigma_{u}^{2} \text { (s.e.) }\end{array}$} & \multirow[b]{2}{*}{$n$} & \multicolumn{2}{|l|}{ T3 } & \multirow[b]{2}{*}{$95 \% \mathrm{Cl}$} & \multirow[b]{2}{*}{$\begin{array}{l}\text { Between school class } \\
\text { variance } \sigma_{u}^{2} \text { (s.e.) }\end{array}$} \\
\hline & & $b$ & $p$ & & & & $b$ & p & & \\
\hline TPA, all week $(\mathrm{cpm})^{\mathrm{b}}$ & 189 & -30.1 & 0.18 & -74.0 to 13.7 & $0.00(0.00)$ & 150 & -34.8 & 0.13 & -79.3 to 9.7 & $2598.1(9176.8)$ \\
\hline TPA, weekends (cpm) ${ }^{\mathrm{b}}$ & 189 & -40.5 & 0.25 & -110.2 to 29.2 & $0.00(0.00)$ & 150 & -30.2 & 0.37 & -96.1 to 35.6 & $0.00(0.00)$ \\
\hline MVPA, all week (minutes) ${ }^{b}$ & 189 & -1.5 & 0.55 & -6.6 to 3.5 & $0.00(0.00)$ & 150 & -3.6 & 0.19 & -8.9 to 1.8 & $41.2(130.0)$ \\
\hline MVPA, weekends (minutes) ${ }^{b}$ & 189 & -0.6 & 0.88 & -8.0 to 6.9 & $20.3(186.3)$ & 150 & -3.2 & 0.45 & -11.4 to 5.0 & $0.00(0.00)$ \\
\hline Sedentary, all week (minutes) ${ }^{c}$ & 189 & 1.5 & 0.68 & -5.7 to 8.7 & $219.7(150.2)$ & 150 & -9.2 & 0.03 & -17.7 to -0.7 & $448.0(165.2)$ \\
\hline Sedentary, weekends (minutes) ${ }^{c}$ & 189 & 9.2 & 0.09 & -1.4 to 19.9 & 610.4 (294.4) & 150 & -11.3 & 0.04 & -22.3 to -0.4 & $434.2(256.9)$ \\
\hline Screen time $\mathrm{min} /$ day $^{\mathrm{a}}$ & 251 & -2.6 & 0.79 & -21.0 to 15.9 & $4443.5(583.2)$ & 222 & -16.5 & 0.10 & -36.0 to 3.0 & $1552.4(2355.4)$ \\
\hline
\end{tabular}

Results of Mixed Linear Regression adjusted for ${ }^{\mathrm{a}}$ sex, parental education, baseline value, ${ }^{\mathrm{b}}$ monitor wear time ${ }^{\mathrm{c}}$ and MVPA

$b=$ Regression coefficient (beta), $p=$ between intervention and control groups, $\mathrm{Cl}=95 \%$ confidence interval

TPA total physical activity, $\mathrm{cpm}$ counts per minute, MVPA moderate to vigorous physical activity

Subjects are dependent observations between $\mathrm{T} 1$ and $\mathrm{T} 2$ and between $\mathrm{T} 1$ and $\mathrm{T} 3$ 
Table 4 Effects of the intervention on BMl sds at T2 and T3

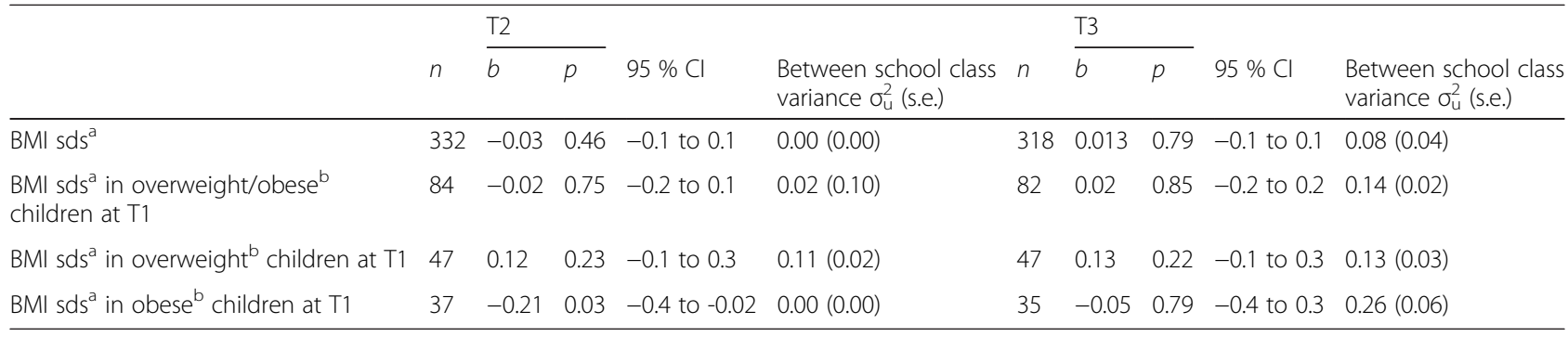

Results of Mixed Linear Regression adjusted for sex, parental education and baseline value

$b=$ Regression coefficient (beta), $p=$ between intervention and control groups, $\mathrm{Cl}=95 \%$ confidence interval

Subjects are dependent observations between $\mathrm{T} 1$ and $\mathrm{T} 2$ and between $\mathrm{T} 1$ and $\mathrm{T} 3$

a Defined according to Karlberg et al. 2001

${ }^{b}$ Defined according to Cole et al. 2012

\section{Discussion}

This study evaluated the effectiveness of the Healthy School Start parental support programme to promote healthy dietary habits and physical activity in children from families with low SES and a high proportion of foreign-born citizens. The results show an intervention effect on outcomes related to intake of unhealthy foods and drinks. There was no intervention effect on physical activity and BMI sds for the whole group. However, BMI sds decreased significantly among obese children. The decrease in consumption of unhealthy foods among boys was sustained at 5 months follow-up. Fidelity to the programme was satisfactory for all three intervention components although only $79 \%$ of the parents participated in the first MI session and $47 \%$ in the second.

\section{Diet}

Our results showed a significantly decreased intake of unhealthy food and drinks by children in the intervention group. At follow-up, this effect was sustained for

Table 5 Fidelity to Ml during intervention

\begin{tabular}{llll}
\hline Ml behaviour & Counsellor A & Counsellor B & $\begin{array}{l}\text { Threshold for } \\
\text { acceptable MI }\end{array}$ \\
\hline Global rating, "Ml spirit" $^{\text {a }}$ & 3.67 & 3.62 & 3.5 \\
Reflection to questions ratio $^{\mathrm{b}}$ & 3.0 & 1.9 & 1 \\
Open questions (\%) $^{\mathrm{c}}$ & 53 & 19 & 50 \\
Complex reflections (\%) $^{\mathrm{d}}$ & 45 & 58 & 40 \\
\hline
\end{tabular}

Ml consistent behaviour of the Ml counsellor in relation to thresholds for acceptable MI

Values are means of MI counsellor behaviour during MI sessions

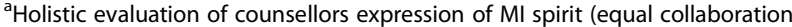

with client about the change + evoking client speech about the change + supporting client's autonomy regarding the change)

${ }^{b}$ Frequency count of counsellor behaviour regarding the specific MI technique reflections in relation to questions; ratio between the total number of questions and reflections stated by the counsellor

${ }^{\mathrm{C}}$ Frequency count of counsellor behaviour regarding questions; percentage of open questions posed by the counsellor

${ }^{\mathrm{d}}$ Frequency count of counsellor behaviour regarding the specific MI technique reflections; percentage of complex reflections stated by the counsellor boys. No effect was found on fruit or vegetable intake. This may be explained by high intake at baseline, when $70 \%$ of the children consumed at least two servings per day of fruit and vegetables at home, which is in line with official recommendations. As many as $40 \%$ of the children reported a daily intake of unhealthy foods at baseline and it is therefore encouraging that the intervention was effective in targeting this problem. A systematic review of parental support interventions has confirmed that children's dietary habits can be improved through parental counselling but that attrition is a problem in low SES groups [27].

Previous studies have used MI counselling with parents to improve children's diet, but most have targeted overweight or obese children. In an Italian study, 372 families with overweight or obese children aged 4-7 years received six MI sessions delivered by pediatricians over one year. A non-significant reduction in unhealthy dietary intake (desserts, fried food, sweetened snacks/ candy and sweetened drinks) in the intervention group was detected [61]. No monitoring of MI fidelity was reported in this study. The High Five for Kids trial [62] included 465 parents of overweight or obese two-toseven-year-old children. The intervention group received four MI sessions delivered by nurses, and three additional supportive telephone calls over one year. There was a non-significant trend towards decreasing intake of fast food and sweetened beverages in the intervention group compared to the control group.

Both studies using MI counselling targeting overweight or obese children, included three or more MI sessions and families did not have low SES, whereas in our study all children were included of which about half of the families had a low educational background. Despite the difference regarding the target group, our results are similar to those previous studies, using MI, including our first trial of this programme where we also found an effect on diet but not on physical activity [36]. This leads us to conclude that MI with parents, together with 
information and practical activities, seems to be effective in improving children's diet in areas of low SES and with a high proportion of foreign born citizens.

\section{Physical activity and sedentary behaviour}

In this study we did not find significant intervention effects on any of the physical activity outcomes. This lack of effect is not surprising considering that at baseline $89 \%$ of all children in the study were sufficiently active according to international recommendations, engaging in at least $60 \mathrm{~min}$ of MVPA per day. Other studies using individual counselling have shown contrasting results [63, 64]. In a Finnish study, parents received counselling once a year over three years and the results showed positive effects on physical activity [64]. In contrast, in another study, face-to-face counselling during 6 months in the home did not result in changes in physical activity or sedentary behaviour [63]. This lack of effect is in line with our study, which also had duration of six months.

Apart from the satisfactory level of physical activity among the children at baseline, the lack of effect could also be due to the short duration of the intervention. The reason for choosing a relatively short intervention period of six months was the waiting-list control design of the study, where the control classes were promised to receive the intervention after the follow-up measurements were finished one year later. Our results are in line with our systematic review [27] where we found that it is difficult to increase children's physical activity through parental support programmes.

Studies using MI as the counselling method have shown contrasting results regarding physical activity. In a 5-month controlled study with nine-year-old children of which a majority had normal weight, parents received $3 \mathrm{MI}$ sessions with additional telephone calls as part of a multicomponent intervention [65]. The intervention also included extra physical activity in school and activities for both children and parents, including group discussions of dietary habits and physical activity. Fidelity to MI was not monitored and physical activity was measured through self-report in interviews with parents. A significant increase in physical activity was reported in the intervention group compared to the control group. Similar results were found in two other studies which both targeted overweight and obese children in primary care $[61,66]$. However, only one of the studies reported MI fidelity [66]. Another study using MI showed no significant differences in physical activity between intervention and control groups [62].

Thus, use of MI either as a single method or as part of a complex intervention, does not have equally convincing results on physical activity as on diet. The studies that did find a positive intervention effect were mostly obesity management studies, where children probably had relatively low activity levels at baseline.

\section{BMI}

Our results showed no difference between the intervention and control groups for weight development after the intervention. However, among obese children $(n=41)$, BMI sds differed significantly between the intervention and control group post-intervention. Parental support interventions to prevent overweight and obesity can be effective [23,26], especially if of high intensity and this is true even in groups with low SES [67-69]. However, nonparticipation and attrition is a problem to be addressed.

Several studies have used MI either as a single method or as part of a complex intervention, but again fidelity is seldom reported. The study by Centis et al [65], using MI counselling, showed a significant decrease in BMI sds between the intervention and the control group in mainly normal weight children. In addition to MI, parents received weekly telephone calls providing support and additional nutrition information, which probably facilitated the change processes. Several MI interventions targeting children with weight problems have failed to detect any significant decreases in BMI [61, 66, 70]. However, the High Five for Kids Trial [62] targeting overweight and obese children found positive intervention effects where BMI sds decreased among girls and children in families with low SES. The BMI2-trial involving 633 parents of overweight children aged 2-8 years found significantly lower BMI in the most intense MI group compared to controls at 2-years follow-up [71]. MI fidelity was monitored during MI training, but not during the intervention. In contrast, another trial in overweight or obese children using MI with parents and additional telephone support had no such effect [72]. However, this was a preliminary study only including 60 children which may explain the lack of significant effects. Therefore, the decrease in BMI sds seen in our study among overweight or obese children is encouraging, even though the effect was transient. We believe that increasing the duration of all the intervention components and the number of MI sessions might yield stronger and more sustainable effects.

\section{Strengths and weaknesses of the study}

This study has several strengths. First, a study protocol has been published ahead of the intervention including a clear description of the intervention theory, components, proposed mediators and outcomes [37]. All materials were pre-tested and culturally adapted to the multinational diversity in the target group by translation into the two most common languages in the target group, Arabic and Somali, as well as adaptation regarding commonly used foods. 
Second, it has a high quality cluster-randomised controlled design, a relatively large sample size, and we used objective assessment of physical activity, sedentary behaviour and anthropometry. Third, we evaluated the process of all three intervention components, and found that it was satisfactory, although only $46 \%$ of the parents participated in both MI sessions. Monitoring MI fidelity is particularly important, and this was done by reliable coders using a valid and reliable instrument.

The fact that MI was delivered by members of the research team with high MI competence constitutes a strength in terms of internal validity, but a limitation in terms of external validity, as school nurses do not presently have this competence. Another limitation was the parental questionnaire, including diet, which has not been validated for the specific target group. Self-report might lead to under reporting of unhealthy behaviours and over reporting of healthy behaviours due to social desirability. Furthermore, the children's usual diets might have been captured more accurately if repeated recalls had been performed. We also faced a high proportion of missing values in questionnaire responses regarding dietary intake and screen time which may have biased the results. We performed a sensitivity analysis in order to account for this which however did not essentially change the results. There may also have been a selection bias in the sample of families, with low participation of families where Swedish is not spoken. Finally, even though we checked for contamination in control classes at school, we cannot exclude the possibility that contamination has taken place in the home environment, which would tend to weaken the effects of the programme.

\section{Implications for future research}

Changes in dietary intake and weight development in children with obesity in our study were significant and comparable to other studies. The intervention showed no effect on physical activity outcomes. There are several lessons to be learnt from this and our previous evaluation [36] of the Healthy School Start programme. Since changes in behaviours and formation of habits can take a long time and effects are short-lived, the programme might benefit from being extended from pre-school class to the first year of school to get stronger intervention effects and to maintain the effects long-term. Regarding the MI component, reminders could perhaps be conducted in the form of telephone calls as done in other studies $[62,65,66]$. The programme might also have been more successful if focus had been on one specific behaviour. Furthermore, cultural diversity in diet and physical activity might have influenced the effect of the intervention. Also, in a prevention study similar to this one, parents often refused to label a concern about diet or physical activity as a problem, but rather as something needing a minor adjustment [73]. It might therefore be necessary to fine tune the use of MI according to the parent's culturally based expectations on health communication and to their views of the target behaviour both when eliciting and when providing information with a preventive purpose. The process evaluation of the HSS programme with teachers and parents [74] suggests that a better tailoring of intervention components to participants' needs and capabilities may increase engagement in the intervention, which could potentially lead to better outcomes.

Achieving sustainability of a programme like this one requires integration into school routines. Delivering the intervention through the school health care services could be suitable as they are an ideal structure for reaching all children and their families independent of social background.

\section{Conclusion}

The Healthy School Start Study shows that it is possible to influence unhealthy dietary intake and weight development in children from families with low SES and a high proportion of foreign-born citizens by providing individual parental support in a school context. However, the positive effects were short-lived. Therefore, the programme probably needs to be prolonged and/or intensified in order to obtain stronger and more sustainable effects, which can be justified based on the principle of proportional universalism. This study may therefore be an important contribution to the further development of evidence-based parental support programmes to prevent overweight and obesity in children in disadvantaged areas.

\section{Competing interests}

The authors declare that they have no competing interests.

\section{Authors' contributions}

GN, LSE, ES and ÅN developed the study design. ÅN, GN and ZZ performed the statistical analyses. GN and $\AA N$ drafted the manuscript. All authors provided critical feedback, contributed to the writing of the manuscript and approved the final manuscript.

\section{Acknowledgements \\ We want to thank all the families and teachers who participated in this intervention. \\ This study was funded by Stockholm County Council Public Health Fund, the Martin Rind Foundation and the Sven Jerring Foundation.}

Received: 3 June 2015 Accepted: 6 January 2016

Published online: 21 January 2016

References

1. Lim SS, Vos T, Flaxman AD, Danaei G, Shibuya K, Adair-Rohani H, et al. A comparative risk assessment of burden of disease and injury attributable to 67 risk factors and risk factor clusters in 21 regions, 1990-2010: a systematic analysis for the Global Burden of Disease Study 2010. Lancet. 2013;380(9859): 2224-60.

2. Biddle SJ, Pearson N, Ross GM, Braithwaite R. Tracking of sedentary behaviours of young people: a systematic review. Prev Med. 2010;51(5):345-51. 
3. Craigie AM, Lake AA, Kelly SA, Adamson AJ, Mathers JC. Tracking of obesityrelated behaviours from childhood to adulthood: a systematic review. Maturitas. 2011;70(3):266-84.

4. Telama R. Tracking of physical activity from childhood to adulthood: a review. Obes Facts. 2009;2(3):187-95.

5. Singh AS, Mulder C, Twisk JW, van Mechelen W, Chinapaw MJ. Tracking of childhood overweight into adulthood: a systematic review of the literature. Obes Rev. 2008;9(5):474-88.

6. Wabitsch M. Overweight and obesity in European children: definition and diagnostic procedures, risk factors and consequences for later health outcome. Eur J Pediatr. 2000;159 Suppl 1:S8-13.

7. Parsons TJ, Power C, Logan S, Summerbell CD. Childhood predictors of adult obesity: a systematic review. Int J Obes Relat Metab Disord. 1999;23 Suppl 8:S1-107.

8. Moraeus L, Lissner L, Yngve A, Poortvliet E, Al-Ansari U, Sjoberg A. Multilevel influences on childhood obesity in Sweden: societal factors, parental determinants and child's lifestyle. Int J Obes (Lond). 2012;36(7):969-76.

9. Magnusson MB, Hulthen L, Kjellgren Kl. Obesity, dietary pattern and physical activity among children in a suburb with a high proportion of immigrants. J Hum Nutr Diet. 2005;18(3):187-94.

10. Sundblom E, Petzold M, Rasmussen F, Callmer E, Lissner L. Childhood overweight and obesity prevalences levelling off in Stockholm but socioeconomic differences persist. Int J Obes (Lond). 2008;32(10):1525-30.

11. Rasmussen M, Krolner R, Klepp Kl, Lytle L, Brug J, Bere E, et al. Determinants of fruit and vegetable consumption among children and adolescents: a review of the literature. Part I: Quantitative studies. Int J Behav Nutr Phys Act. 2006:3:22

12. Ventura AK, Birch LL. Does parenting affect children's eating and weight status? Int J Behav Nutr Phys Act. 2008;5:15.

13. Collins C, Duncanson K, Burrows T. A systematic review investigating associations between parenting style and child feeding behaviours. J Hum Nutr Diet. 2014;27(6):557-68.

14. Vollmer RL, Mobley AR. Parenting styles, feeding styles, and their influence on child obesogenic behaviors and body weight. A review. Appetite. 2013; 71:232-41.

15. Davison KK, Cutting TM, Birch LL. Parents' activity-related parenting practices predict girls' physical activity. Med Sci Sports Exerc. 2003;35(9):1589-95.

16. Ferreira I, van der Horst K, Wendel-Vos W, Kremers S, van Lenthe FJ, Brug J. Environmental correlates of physical activity in youth - a review and update. Obes Rev. 2007:8(2):129-54.

17. Seabra AC, Seabra AF, Mendonca DM, Brustad R, Maia JA, Fonseca AM, et al. Psychosocial correlates of physical activity in school children aged 8-10 years. Eur J Public Health. 2013;23(5):794-8.

18. Verloigne M, Van Lippevelde W, Maes L, Brug J, De Bourdeaudhuij I. Familyand school-based correlates of energy balance-related behaviours in 10-12year-old children: a systematic review within the ENERGY (EuropeaN Energy balance Research to prevent excessive weight Gain among Youth) project. Public Health Nutr. 2012;15(8):1380-95.

19. Mullie $P$, Clarys $P$, Hulens $M$, Vansant $G$. Dietary patterns and socioeconomic position. Eur J Clin Nutr. 2010;64(3):231-8.

20. Elinder LS, Heinemans N, Hagberg J, Quetel AK, Hagstromer M. A participatory and capacity-building approach to healthy eating and physical activity- SCIPschool: a 2-year controlled trial. Int J Behav Nutr Phys Act. 2012;9:145.

21. Sallis JF, Prochaska JJ, Taylor WC. A review of correlates of physical activity of children and adolescents. Med Sci Sports Exerc. 2000;32(5):963-75.

22. Summerbell CD, Waters E, Edmunds LD, Kelly S, Brown T, Campbell KJ. Interventions for preventing obesity in children. Cochrane database of systematic reviews (Online). 2005;3:CD001871.

23. Golley RK, Hendrie GA, Slater A, Corsini N. Interventions that involve parents to improve children's weight-related nutrition intake and activity patterns what nutrition and activity targets and behaviour change techniques are associated with intervention effectiveness? Obes Rev. 2011;12(2):114-30.

24. Hingle MD, O'Connor TM, Dave JM, Baranowski T. Parental involvement in interventions to improve child dietary intake: a systematic review. Prev Med. 2010;51(2):103-11.

25. O'Connor TM, Jago R, Baranowski T. Engaging parents to increase youth physical activity a systematic review. Am J Prev Med. 2009;37(2):141-9.

26. Hendrie GA, Brindal E, Corsini N, Gardner C, Baird D, Golley RK. Combined home and school obesity prevention interventions for children: what behavior change strategies and intervention characteristics are associated with effectiveness? Health Educ Behav. 2012;39(2):159-71.
27. Kader M, Sundblom E, Elinder LS. Effectiveness of universal parental support interventions addressing children's dietary habits, physical activity and bodyweight: A systematic review. Prev Med. 2015;77:52-67.

28. Jones TL, Prinz RJ. Potential roles of parental self-efficacy in parent and child adjustment: a review. Clin Psychol Rev. 2005;25(3):341-63.

29. Miller WR, Rollnick S. Motivational interviewing: Helping people change. 3rd ed. New York: Guilford Press; US; 2013.

30. Armstrong MJ, Mottershead TA, Ronksley PE, Sigal RJ, Campbell TS, Hemmelgarn BR. Motivational interviewing to improve weight loss in overweight and/or obese patients: a systematic review and meta-analysis of randomized controlled trials. Obes Rev. 2011;12(9):709-23.

31. Martins RK, McNeil DW. Review of motivational interviewing in promoting health behaviors. Clin Psychol Rev. 2009;29(4):283-93.

32. Hardcastle SJ, Taylor AH, Bailey MP, Harley RA, Hagger MS. Effectiveness of a motivational interviewing intervention on weight loss, physical activity and cardiovascular disease risk factors: a randomised controlled trial with a 12month post-intervention follow-up. Int J Behav Nutr Phys Act. 2013;10:40.

33. Dawson AM, Brown DA, Cox A, Williams SM, Treacy L, Haszard J, et al. Using motivational interviewing for weight feedback to parents of young children. J Paediatr Child Health. 2014;50(6):461-70.

34. Schwartz RP, Hamre R, Dietz WH, Wasserman RC, Slora EJ, Myers EF, et al. Office-based motivational interviewing to prevent childhood obesity: a feasibility study. Arch Pediatr Adolesc Med. 2007:161(5):495-501.

35. Williams AA, Wright KS. Engaging families through motivational interviewing Pediatr Clin North Am. 2014;61(5):907-21.

36. Nyberg G, Sundblom E, Norman A, Bohman B, Hagberg J, Elinder LS. Effectiveness of a universal parental support programme to promote healthy dietary habits and physical activity and to prevent overweight and obesity in 6-year-old children: the healthy school start study, a cluster-randomised controlled trial. PLoS One. 2015;10(2), e0116876.

37. Nyberg G, Sundblom E, Norman A, Elinder LS. A healthy school start - parental support to promote healthy dietary habits and physical activity in children: design and evaluation of a cluster-randomised intervention. BMC Public Health. 2011;11:185.

38. Årsrapport barnhälsovården (Annual report on child health care). Stockholm: Stockholms Läns Landsting 2013.

39. Haynos AF, O'Donohue WT. Universal childhood and adolescent obesity prevention programs: review and critical analysis. Clin Psychol Rev. 2012; 32(5):383-99.

40. Baranowski T, Perry C, Parcel G. How individuals, environments, and health behavoir interact: Social cognitive theory. In: Glanz KRB, Lewis FM, editors. Health Behaviour and Health Education. Theory, Research, and Practice. San Francisco: Jossey-Bass; 2002.

41. Bandura A. Social Foundations of Thought and Action: A Social Cognitive Theory. NJ: Prentice-Hall: Englewood Cliffs; 1986.

42. Fraser M, Richman J, Galinsky M, Day S. Intervention Research. New York: Oxford University Press; 2009.

43. von Haartman F, Sundblom E, Schafer EL. Föräldrastöd Till Hälsosamma Matvanor och Fysisk Aktivitet - en Kunskapsöversikt (Parental Support for Healthy Dietary Habits and Physical Activity - a Review). Karolinska Institutets folkhälsoakademi: Stockholm; 2009.

44. Johnson CC, Osganian SK, Budman SB, Lytle LA, Barrera EP, Bonura SR et al. CATCH: family process evaluation in a multicenter trial. Health Educ Q. 1994; Suppl 2:S91-106

45. Bayer O, von Kries R, Strauss A, Mitschek C, Toschke AM, Hose A, et al. Short- and mid-term effects of a setting based prevention program to reduce obesity risk factors in children: a cluster-randomized trial. Clin Nutr. 2009;28(2):122-8.

46. Moyers T, Martin, T, Manuel, JK, Miller, WR, Ernst, D. Revised Global Scales: Motivational Interviewing Treatment Integrity 3.1.1 (MITI 3.1.1). University of New Mexico Center on Alcoholism, Substance Abuse and Addictions (CASAA). Accessed 17 Feb. 2014

47. de Vries S, Bakker I, Hopman-Rock M, Hirasing R, van Mechelen W. Clinimetric review of motion sensors in children and adolescents. J Clin Epidemiol. 2006; 59(7):670-80.

48. Sherar LB, Griew P, Esliger DW, Cooper AR, Ekelund U, Judge $K$, et al. International children's accelerometry database (ICAD): design and methods. BMC Public Health. 2011:11:485.

49. Trost SG, Loprinzi PD, Moore R, Pfeiffer KA. Comparison of accelerometer cut points for predicting activity intensity in youth. Med Sci Sports Exerc. 2011;43(7):1360-8. 
50. Ridgers ND, Salmon J, Ridley K, O'Connell E, Arundell L, Timperio A. Agreement between activPAL and ActiGraph for assessing children's sedentary time. Int J Behav Nutr Phys Act. 2012;9:15.

51. Trost SG, Ward DS, Moorehead SM, Watson PD, Riner W, Burke JR. Validity of the computer science and applications (CSA) activity monitor in children. Med Sci Sports Exerc. 1998;30(4):629-33.

52. Bennett CA, de Silva-Sanigorski AM, Nichols M, Bell AC, Swinburn BA. Assessing the intake of obesity-related foods and beverages in young children: comparison of a simple population survey with $24 \mathrm{~h}$-recall. Int J Behav Nutr Phys Act. 2009;6:71.

53. Cole TJ, Lobstein T. Extended international (IOTF) body mass index cut-offs for thinness, overweight and obesity. Pediatr Obes. 2012;7(4):284-94.

54. Karlberg J, Luo ZC, Albertsson-Wikland K. Body mass index reference values (mean and SD) for Swedish children. Acta Paediatr. 2001;90(12):1427-34.

55. Galobardes B, Shaw M, Lawlor DA, Lynch JW, Davey SG. Indicators of socioeconomic position (part 1). J Epidemiol Community Health. 2006;60(1):7-12.

56. Galobardes B, Shaw M, Lawlor DA, Lynch JW, Davey SG. Indicators of socioeconomic position (part 2). J Epidemiol Community Health. 2006;60(2):95-101.

57. Urbana utvecklingsområden (Urban developemnt areas). Statistisk uppföljning utifrån sju indikatorer: Ministry of employment Sweden 2012. Report No: Dnr A2012/4115/IU.

58. Twisk JWR. Applied Multilevel Analysis, A Practical Guide. Cambridge UK: Cambrigde University Press; 2006.

59. Ekelund U, Luan J, Sherar LB, Esliger DW, Griew P, Cooper A. Moderate to vigorous physical activity and sedentary time and cardiometabolic risk factors in children and adolescents. Jama. 2012;307(7):704-12.

60. Campbell MK, Thomson S, Ramsay CR, MacLennan GS, Grimshaw JM. Sample size calculator for cluster randomized trials. Comput Biol Med. 2004;34(2):113-25.

61. Davoli AM, Broccoli S, Bonvicini L, Fabbri A, Ferrari E, D'Angelo S, et al. Pediatrician-led motivational interviewing to treat overweight children: an RCT. Pediatrics. 2013;132(5):e1236-46.

62. Taveras EM, Gortmaker SL, Hohman KH, Horan CM, Kleinman KP, Mitchell K, et al. Randomized controlled trial to improve primary care to prevent and manage childhood obesity: the high five for kids study. Arch Pediatr Adolesc Med. 2011;165(8):714-22.

63. Anand SS, Davis AD, Ahmed R, Jacobs R, Xie C, Hill A, et al. A family-based intervention to promote healthy lifestyles in an aboriginal community in Canada. Can J Public Health. 2007;98(6):447-52.

64. Saakslahti A, Numminen P, Salo P, Tuominen J, Helenius H, Valimaki I. Effects of a three-year intervention on children's physical activity from age 4 to 7. Pediatr Exerc Sci. 2004;16:167-80.

65. Centis E, Marzocchi R, Di Luzio R, Moscatiello S, Salardi S, Villanova N, et al. A controlled, class-based multicomponent intervention to promote healthy lifestyle and to reduce the burden of childhood obesity. Pediatr Obes. 2012; 7(6):436-45.

66. Tucker SJ, Ytterberg KL, Lenoch LM, Schmit TL, Mucha DI, Wooten JA, et al. Reducing pediatric overweight: nurse-delivered motivational interviewing in primary care. J Pediatr Nurs. 2013;28(6):536-47.

67. Barkin SL, Gesell SB, Po'e EK, Escarfuller J, Tempesti T. Culturally tailored, family-centered, behavioral obesity intervention for Latino-American preschool-aged children. Pediatrics. 2012;130(3):445-56.

68. Slusser W, Frankel F, Robison K, Fischer H, Cumberland WG, Neumann C. Pediatric overweight prevention through a parent training program for 2-4 year old Latino children. Child Obes. 2012;8(1):52-9.

69. Yin Z, Parra-Medina D, Cordova A, He M, Trummer V, Sosa E, et al. Miranos! Look at us, we are healthy! An environmental approach to early childhood obesity prevention. Child Obes. 2012:8(5):429-39.

70. van Grieken A, Veldhuis L, Renders CM, Borsboom GJ, van der Wouden JC, Hirasing RA, et al. Population-based childhood overweight prevention: outcomes of the 'Be active, eat right' study. PLoS One. 2013;8(5), e65376.

71. Resnicow K, McMaster F, Bocian A, Harris D, Zhou Y, Snetselaar L, et al. Motivational interviewing and dietary counseling for obesity in primary care: an RCT. Pediatrics. 2015;135(4):649-57.

72. Small L, Bonds-McClain D, Melnyk B, Vaughan L, Gannon AM. The preliminary effects of a primary care-based randomized treatment trial with overweight and obese young children and their parents. J Pediatr Health Care. 2014;28(3):198-207.

73. Norman A, Berlin A, Sundblom E, Elinder LS, Nyberg G. Stuck in a vicious circle of stress. Parental concerns and barriers to changing children's dietary and physical activity habits. Appetite. 2014;87C:137-42.
74. Norman $\AA$, Nyberg, G, Schäfer Elinder L, Berlin A, One size does not fit allqualitative process evaluation of the Healthy School Start parental support programme to prevent overweight and obesity among children in disadvantaged areas in Sweden, Accepted for publication in BMC Public Health 2016.

\section{Submit your next manuscript to BioMed Central and we will help you at every step:}

- We accept pre-submission inquiries

- Our selector tool helps you to find the most relevant journal

- We provide round the clock customer support

- Convenient online submission

- Thorough peer review

- Inclusion in PubMed and all major indexing services

- Maximum visibility for your research

Submit your manuscript at www.biomedcentral.com/submit
Biomed Central 